\title{
HUMAN T CELL RESPONSES TO HPV 16 E2 GENERATED WITH MONOCYTE-DERIVED DENDRITIC CELLS
}

\author{
Emma J. Davidson ${ }^{1,2}$, Michael D. Brown ${ }^{3}$, Deborah J. Burt ${ }^{1}$, Joanna L. Parish ${ }^{4}$, Kevin Gaston ${ }^{4}$, Henry C. Kitchener ${ }^{2}$, \\ Simon N. STACEY ${ }^{3}$ and Peter L. STERN ${ }^{1 *}$ \\ ${ }^{1}$ CRC Immunology Group, Paterson Institute for Cancer Research, Christie Hospital NHS Trust, Manchester, United Kingdom \\ ${ }^{2}$ Academic Department of Obstetrics and Gynaecology and Reproductive Healthcare, University of Manchester, St Mary's Hospital, \\ Manchester, United Kingdom \\ ${ }^{3}$ CRC Molecular Biology Group, Paterson Institute for Cancer Research, Christie Hospital NHS Trust, Manchester, United \\ Kingdom \\ ${ }^{4}$ Department of Biochemistry, University of Bristol, Bristol, United Kingdom
}

\begin{abstract}
Persistent infection with human papillomavirus (HPV) type 16 has been implicated in the etiology of cervical cancer. The E2 protein is required early in viral infection and therefore may serve as a useful immune target for a vaccine aimed at prevention or therapy of premalignant lesions. Dendritic cells (DC) prepared from monocytes and pulsed with bacterially produced HPV 16 E2 C-terminus protein were used to stimulate autologous $T$ cells over several rounds of stimulation. $T$ cells were tested for $\gamma$-interferon release by ELISPOT and for cytotoxic activity by ${ }^{51}$ chromium release assays. To generate E2-expressing target cells for cytotoxicity assays, we constructed a recombinant vaccinia virus encoding HPV 16 E2, which was used to infect autologous Epstein-Barr virus-transformed lymphoblastoid cell lines (LCL). The results show that DC pulsed with E2 C-terminus protein induce $\gamma$-interferon-releasing $T$ cells as demonstrated by ELISPOT. Furthermore, we demonstrate E2-specific lysis of vaccinia-E2 infected autologous LCL by CD8+ cytotoxic $T$ lymphocytes (CTL). E2-specific CTL did not lyse untreated autologous LCL or LCL infected with wild-type vaccinia and showed low levels of cytotoxicity against natural killer cell-sensitive $\mathrm{K562}$ cells. In addition, T cells stimulated with DC in the absence of E2 failed to demonstrate lysis of vaccinia-E2-labeled targets. Phenotypically, CTL populations were CD3+/CD8+. These results will facilitate the study of naturally occurring $T$-cell responses to HPV E2 in patients with cervical intraepithelial neoplasia and the development of immunotherapeutic strategies designed to treat this and other HPV-associated diseases.

(C) 2001 Wiley-Liss, Inc.
\end{abstract}

Key words: human papillomavirus (HPV); E2 protein; dendritic cells; cytotoxic T lymphocytes (CTL); $\gamma$-interferon ELISPOT; primary immune responses; cervical intraepithelial neoplasia (CIN); cervical cancer; vaccines

Persistent infection with oncogenic human papillomaviruses (HPV) such as HPV 16 is necessary for the development of invasive cervical carcinoma. ${ }^{1-4}$ Natural immunity plays an important role in the control of HPV infection,,$^{5-7}$ and the identification of HPV-specific immunity in patients ${ }^{8-11}$ has provided the impetus for the development of vaccines to both prevent and treat HPVassociated disease. Most therapeutic vaccines have focused on stimulating specific cell-mediated immunity to HPV 16 E6 and E7 proteins, which are expressed in all stages of HPV-related disease development and are therefore appropriate immune targets in high grade and malignant disease. ${ }^{12,13}$

Other early viral proteins could also be immune targets for vaccines aimed at treating HPV-associated disease. HPV 16 E2 is a 42-kDa protein comprising 3 functional domains: a 200-amino acid amino-terminal (N-terminal) activation domain ${ }^{14}$ and a 100 amino acid carboxy-terminal (C-terminal) DNA-binding domain, ${ }^{15}$ joined by a flexible hinge region. ${ }^{16}$ E2 is necessary for viral replication ${ }^{17,18}$ and for the transcriptional control of other viral proteins, including E6 and E7. ${ }^{19}$ In cervical dysplasia, E2 expression is highest in koilocytes and decreases with increasing cervical intraepithelial neoplasia (CIN) grade. ${ }^{20}$ In the cottontail rabbit papillomavirus (CRPV) model, immunization of rabbits with DNA plasmid-encoding CRPV E2 prevented the development of skin papillomas. ${ }^{21,22}$ These studies support the use of E2 as an immunologic target in vaccines for the protection or therapy of HPV infection and CIN. Thus virus-like particles composed of the viral capsid proteins ( $\mathrm{L} 1$ and L2) for use in prophylaxis of HPV-associated disease have been modified to include E2 and E7 proteins. The idea is that generation of cellular immunity against the early genes may induce the regression of subclinical infections that result from imperfect neutralization of virus by antibodies. ${ }^{23}$ However, E2 gene disruption is associated with invasive disease, mechanistically via deregulation of viral oncogene expression. This association could provide an escape from E2-specific immunity, although integration into the cellular genome is not always seen in higher grade lesions and carcinomas. ${ }^{24}$

Whether E2-specific cellular immune responses play a role in the natural history of HPV infection is not known. Two studies have demonstrated helper T-cell responses to HPV 16 E2 in patients with cervical neoplasia. Lehtinen et al. ${ }^{25}$ showed T-cell proliferation in response to E2 peptides in 3 of 6 women with CIN 3 or cervical carcinoma. Bontkes et al. ${ }^{26}$ investigated helper T-cell responses to the $\mathrm{C}$-terminus and $\mathrm{N}$-terminus of the HPV $16 \mathrm{E} 2$ protein in a cohort of 74 women with CIN. Although responses to the N-terminus were nonspecific, longitudinal analysis revealed that responses to the $\mathrm{C}$-terminus occurred coincident with viral clearance. ${ }^{26}$ Cytotoxic T lymphocyte (CTL) responses to HPV 16 E2 have not been extensively studied. Konya et al. ${ }^{27}$ identified an human leucocyte antigen (HLA)-A2 E2 epitope that was capable of eliciting peptide-specific CTL in normal donors. However, the peptide-based epitope approach is restricted by the necessary use of immunodominant or subdominant peptides and by the requirement for a particular HLA type. ${ }^{28,29}$

In the present study we investigated whether HPV 16 E2specific CTL can be induced in normal volunteers using E2 Cterminus protein-pulsed autologous dendritic cells (DC). Using the intact protein provides all potential peptide epitopes if processed and presented by efficient antigen-presenting cells (APC) like DC, which are capable of activating naïve $\mathrm{T}$ cells. ${ }^{30} \mathrm{~A}$ recombinant

Grant sponsor: Cancer Research Campaign; Grant sponsor: BBSRC; Grant sponsor: Enact Pharma PLC; Grant sponsor: Royal Society; Grant sponsor: Joseph Starkey Fellowship from Wigan Cancer Research Fund.

Dr. Stacey's current address is: deCODE Genetics, Lynghals 1, Reykjavik, Iceland.

*Correspondence to: CRC Immunology Group, Paterson Institute for Cancer Research, Christie Hospital NHS Trust, Manchester M20 4BX, UK. Fax: +44-161-446-3109. E-mail: pstern@ picr.man.ac.uk

Received 21 March 2001; Revised 30 May 2001; Accepted 4 July 2001 
vaccinia virus encoding HPV $16 \mathrm{E} 2$ was constructed and used to infect autologous Epstein-Barr virus-transformed lymphoblastoid cell lines (LCL) as targets in cytotoxicity assays and CTL were also tested by $\gamma$-interferon $(\gamma$-IFN) ELISPOT.

\section{MATERIAL AND METHODS \\ Production of E2 C-terminus protein}

The 86-amino acid HPV 16 E2 C-terminus protein was expressed in Escherichia coli XL1-blue cells using the expression vector pKK-E2Ct and purified according to Webster et al. ${ }^{31}$ The protein was shown to be a single band by Coomassie-stained SDS-PAGE and reactive with a polyclonal rabbit anti-E2 C-terminus antibody by Western blot (data not shown).

\section{Description of vaccinia-E208 construction}

The E2 open reading frame (ORF) from HPV 16 (nucleotides 2756-3851) was amplified by PCR and cloned into vaccinia virus insertion vector $\mathrm{p} 1108$, which placed the ORF under the control of the $7.5 \mathrm{~K}$ early/late vaccinia virus promoter. The expression cassette was then inserted into the TK locus of vaccinia virus strain WR by homologous recombination, followed by selection for a cotransferred gpt marker (guanine phosphoribosyltransferase). Five clones were isolated by several rounds of plaque purification and tested for successful insertion of the E2 gene into the TK locus using PCR. Expression of the E2 protein by recombinant virus was investigated by immunofluorescence microscopy of infected $\mathrm{HeLa}$ cells using a rabbit polyclonal antibody against the C-terminal region of the $\mathrm{E} 2$ protein $^{31}$ at a concentration of 1:100 and a swine anti-rabbit-fluorescein isothiocyanate antibody at 1:40 (Dako). Vaccinia-E2 infected CV-1 cells were also analyzed by Western blot for E2 protein expression. Cells infected with wild-type vaccinia and cells infected with vaccinia-E2 were prepared $24 \mathrm{hr}$ before analysis by SDS-PAGE to allow maximal protein expression by the cells. Cellular protein was extracted, reduced and fractionated by $10 \%$ SDS-PAGE before being transferred to nitrocellulose. Rabbit anti-E2 C-terminus polyclonal antibody was used at a concentration of 1:50 followed by development using enhanced chemiluminescence (Amersham-Pharmacia).

\section{Isolation of peripheral blood mononuclear cells (PBMC) and culture of DC}

Peripheral blood of 3 healthy donors was obtained every 7 days. Donor A was HLA A2 negative; donors B and C were HLA A2 positive. Venous blood was heparinized (6000 IU heparin/20 ml blood) and $10 \mathrm{ml}$ layered onto $10 \mathrm{ml}$ Lymphoprep lymphocyte separation medium (LSM, Nycomed) and centrifuged at $900 \mathrm{~g}$ for 20 min at $20^{\circ} \mathrm{C}$. PBMC were collected from the LSM interface and washed by centrifuging at $400 \mathrm{~g}$ in PBS for $3 \times 10 \mathrm{~min}$. PBMC at $4 \times 10^{6}$ cells $/ \mathrm{ml}$ in X-VIVO 10 medium (Biowhittaker UK Ltd) supplemented with $2 \mathrm{mM}$ glutamine were transferred to tissue culture plates and incubated at $37^{\circ} \mathrm{C}$ for $2 \mathrm{hr}$. The nonadherent peripheral blood lymphocytes (PBL) were collected and $3 \mathrm{ml}$ of $\mathrm{X}$-VIVO 10 supplemented with $2 \mathrm{mM}$ glutamine (Life Technologies), $100 \mathrm{ng} / \mathrm{ml}$ granulocyte-macrophage colony-stimulating factor (GM-CSF) and $50 \mathrm{ng} / \mathrm{ml}$ interleukin-4 (IL-4; both from R \& D systems) was added to each well of adherent cells and the plates incubated at $37^{\circ} \mathrm{C}$ in $5 \% \mathrm{CO}_{2}$. Fresh medium supplemented with GM-CSF and IL-4 was added to the cultures on day 4. All T-cell stimulation was with day 7 DC. As described below, the DC were matured with lipopolysaccharide (LPS) on day 6 and E2 antigen added for effective processing at this time. Peptides do not need the latter so were added on day 7 .

\section{DC pulsing with E2 C-terminus protein}

$\mathrm{N}$-[1-(2,3-dioleoyloxy)propyl]-N,N,N-trimethylammonium methyl sulphate (DOTAP) liposomal transfection reagent $(25 \mu \mathrm{g})$ (Roche) and bacterially produced purified HPV 16 E2 C-terminus protein $(10 \mu \mathrm{g})$ were mixed at room temperature in polystyrene tubes for $20 \mathrm{~min}$. After this time, $3 \times 10^{5} \mathrm{DC}$ in $400 \mu \mathrm{X}$-VIVO 10 with $100 \mathrm{ng} / \mathrm{ml} \mathrm{GM-CSF}$ were added to the DOTAP/protein mixture. The DC were incubated for $4 \mathrm{hr}$ at $37^{\circ} \mathrm{C}$, washed twice, resuspended in $1 \mathrm{ml} \mathrm{X-VIVO} 10$ supplemented with $100 \mathrm{ng} / \mathrm{ml}$ GM-CSF, $50 \mathrm{ng} / \mathrm{ml} \mathrm{IL-4} \mathrm{and} 10 \mathrm{ng} / \mathrm{ml}$ LPS (Sigma) and incubated at $37^{\circ} \mathrm{C}$ to mature the DC. After $24 \mathrm{hr}$, DC were harvested, washed twice and resuspended in $100 \mu$ l RPMI 1640 (Life Technologies).

\section{DC pulsing with influenza matrix peptide}

Day 6 DC were suspended in $1 \mathrm{ml} \mathrm{X-VIVO} 10$ supplemented with $100 \mathrm{ng} / \mathrm{ml} \mathrm{GM-CSF}, 50 \mathrm{ng} / \mathrm{ml} \mathrm{IL-4}$ and $10 \mathrm{ng} / \mathrm{ml} \mathrm{LPS}$, and matured at $37^{\circ} \mathrm{C}$ for $24 \mathrm{hr}$. After this time, $3 \times 10^{5} \mathrm{DC}$ in $400 \mu \mathrm{l}$ $\mathrm{X}$-VIVO 10 with $100 \mathrm{ng} / \mathrm{ml} \mathrm{GM}-\mathrm{CSF}$ was added to $10 \mu \mathrm{g}$ HLA A2.1 binding influenza matrix peptide 58-66, sequence GILGFVFTL (Alta Bioscience) and incubated for $4 \mathrm{hr}$ at $37^{\circ} \mathrm{C}$. The DC were washed twice and suspended in $100 \mu \mathrm{l}$ RPMI.

\section{CD4 depletion of $P B L$}

PBL were suspended in $80 \mu$ l of ice cold Minimacs buffer $(0.5 \%$ BSA, $0.005 \mathrm{M}$ EDTA in PBS, filter sterilized) and $20 \mu \mathrm{l} \mathrm{CD4+}$ beads (Miltenyi Biotech) per $10^{7}$ cells. The cells were incubated at $4^{\circ} \mathrm{C}$ for $20 \mathrm{~min}$, then washed with Minimacs buffer at $400 \mathrm{~g}$ for 10 min. The Minimacs column (Miltenyi Biotech) was prepared by attaching to the magnet and washing twice with $0.5 \mathrm{ml}$ Minimacs buffer. The cells were suspended in $0.5 \mathrm{ml}$ buffer and added to the top of the prepared column. The CD4-depleted fraction was collected as the column flow-through. The rationale was to favor CTL responses without removing all the T-helper activity required for optimal activation of CD8 cells.

\section{Generation of E2 CTL}

Autologous CD4-depleted PBL at a concentration of $3 \times 10^{6} / \mathrm{ml}$ in RPMI 1640 supplemented with $10 \%$ human $\mathrm{AB}$ serum (Quest Biomedical), $100 \mu \mathrm{g} / \mathrm{ml}$ streptomycin and $100 \mathrm{IU} / \mathrm{ml}$ penicillin (Life Technologies) were added to E2 protein-loaded DC with 10 $\mathrm{ng} / \mathrm{ml} \mathrm{IL-7} \mathrm{(R} \mathrm{\&} \mathrm{D} \mathrm{systems)} \mathrm{and} \mathrm{cultured} \mathrm{for} 7$ days. Every 2 days, $1 \mathrm{ml}$ of spent medium was replaced with $1 \mathrm{ml}$ fresh medium supplemented with $10 \mathrm{ng} / \mathrm{ml}$ IL-7. After 7 days in culture, T cells were restimulated using fresh day 7 DC pulsed with protein/ peptide according to the methods described above. Cultures were incubated overnight at $37^{\circ} \mathrm{C}$ before being supplemented with 10 $\mathrm{ng} / \mathrm{ml} \mathrm{IL-7} \mathrm{and} 20 \mathrm{IU} / \mathrm{ml}$ IL-2 (R \& D systems). The cultures were then incubated for 7 days. Every 2 days, $1 \mathrm{ml}$ spent medium was replaced with $1 \mathrm{ml}$ fresh medium supplemented with $10 \mathrm{ng} / \mathrm{ml} \mathrm{IL-7}$ and $20 \mathrm{IU} / \mathrm{ml} \mathrm{IL-2.} \mathrm{T} \mathrm{cells} \mathrm{were} \mathrm{tested} \mathrm{in} \mathrm{cytotoxicity} \mathrm{assays} \mathrm{after}$ 1 or several rounds of stimulation.

\section{ELISPOT assay}

CD4-depleted PBL as above were added to autologous DC (loaded or not with E2 protein/flu peptide) and cultured in RPMI + $10 \% \mathrm{AB}$ serum for 4 or 7 days. The 7-day cultures were restimulated with either autologous PBMC or DC (with or without antigen). ELISPOT ${ }^{2}$ was performed 4 days after the first or second stimulation. The cultures were harvested, washed and seeded in 3 replicate wells at 4 doubling dilutions from $2 \times 10^{5}$ cells/well of a multiscreen 96-well Immobilon-P filtration plate (Millipore) coated with anti $\gamma$-interferon antibody [capture mAb (1-D1K), ELISPOT assay kit, Mabtech] and processed as per kit instructions. Initial experiments incubated PBMC at $2 \times 10^{6} / \mathrm{ml}$ with 10 $\mu \mathrm{g} / \mathrm{ml}$ of flu peptide or E2 protein in the ELISPOT plates for $48 \mathrm{hr}$. Spots were counted at each cell density using a dissecting microscope, scores normalized and the mean and standard errors calculated. The number of specific events was calculated by subtracting the normalized number of spots in control wells from those in antigen-stimulated wells.

\section{Cytotoxicity assay}

Preparation of target cells. First, $10^{7} \mathrm{PBMC}$ were suspended in $200 \mu \mathrm{l}$ of B95-8 Epstein Barr virus stock (donated by Dr. M. Mackett, Molecular Biology Group, PICR, UK). The cells were incubated at $37^{\circ} \mathrm{C}$ for $1 \mathrm{hr}$, washed and resuspended in RPMI + $10 \%$ FCS, $2 \mathrm{mM}$ glutamine, $100 \mu \mathrm{g} / \mathrm{ml}$ streptomycin and 100 $\mathrm{IU} / \mathrm{ml}$ penicillin at $5 \times 10^{5} / \mathrm{ml}$. Phytohaemagglutinin (Murex 
Diagnostics) was added at $0.5 \mu \mathrm{g} / \mathrm{ml}$ and cells plated out at 2 $\mathrm{ml} / \mathrm{well}$. The cultures were checked weekly and $1 \mathrm{ml}$ medium/well replaced with fresh RPMI $+10 \%$ FCS as appropriate. $1 \times 10^{6}$ autologous LCL cells were pelleted and infected for $1 \mathrm{hr}$ at $37^{\circ} \mathrm{C}$ with $10 \mathrm{pfu} / \mathrm{cell}$ of virus, $24 \mathrm{hr}$ before the assay. Viruses used were WR (wild-type vaccinia) and vE208 (recombinant vaccinia virus encoding HPV 16 E2). After $1 \mathrm{hr}$ the cells were washed 3 times and incubated overnight in RPMI $+10 \%$ FCS before labeling with ${ }^{51} \mathrm{Cr}$. All target cell lines were labeled with $100 \mu \mathrm{Ci}(20 \mu \mathrm{l})$ of $\mathrm{Na}_{2}{ }^{51} \mathrm{CrO}_{4}$ (NEN) for $1 \mathrm{hr}$ on the day of the assay, washed 3 times and placed in a 96-well plate in aliquots of $2 \times 10^{3}$ targets/well.

Preparation of effector cells. T cells were washed and resuspended in RPMI $+10 \% \mathrm{AB}$ serum to give a maximum concentration of $2 \times 10^{5}$ effectors/well. Serial dilutions were prepared, with each cell concentration represented in triplicate. Maximum ${ }^{51} \mathrm{Cr}$ release was determined from supernatants of target cells that were lysed with $100 \mu \mathrm{l}$ of PBS/2\% Tween 20 and spontaneous ${ }^{51} \mathrm{Cr}$ release was determined by adding target cells only to the wells. Plates were incubated at $37^{\circ} \mathrm{C}$ for $4 \mathrm{hr}$ and $100 \mu \mathrm{l}$ of the supernatant from each well transferred to Lumaplates (Packard) and left to dry overnight. The plates were read in a Top Count plate reader (Packard). Specific lysis was calculated as: (specific release - spontaneous release $) \div$ (maximum release - spontaneous release) $\times 100$. Spontaneous release was less than $20 \%$ of maximum release. Samples were considered positive when the difference in specific lysis between the recombinant vaccinia virus infected LCL and the wild-type infected LCL was more than $10 \%$ over 2 or more $\mathrm{E}: \mathrm{T}$ ratios.

\section{RESULTS}

\section{Phenotypic analysis of $D C$}

DC were prepared from adherent PBMC in serum-free medium with GM-CSF and IL-4. After 6 days of culture, DC were pulsed with E2 C-terminus protein and DOTAP or with DOTAP alone for $4 \mathrm{hr}$ and then matured with LPS for $24 \mathrm{hr}$. Flu peptide was added on day 7 to matured DC. The purity of the resulting DC populations was determined by flow cytometry for the cell surface markers CD1a, HLA-DR, CD80 and CD86. High proportions of the monocyte-derived DC populations were positive for CD1a $(66 \%)$, HLA-DR (96\%), CD80 (49\%) and CD86 (61\%).

\section{E2-specific CD8+ T-cell responses: ELISPOT}

PBMC were pulsed with E2 C-terminus protein and added to the ELISPOT plate at $2 \times 10^{6} / \mathrm{ml}$ for $48 \mathrm{hr}$. Untreated PBMC were included as a negative control and HLA A2 influenza peptidepulsed PBMC as a positive control. A response for the influenza peptide was detected in the 2 HLA A2 -positive donors (12.5 spots $/ 10^{5}$ cells for donor B; 8.5 spots $/ 10^{5}$ cells for donor C), but not in the HLA A2-negative donor ( 0 spots $/ 10^{5}$ cells for donor A). No responses were detected for PBMC pulsed with E2 C-terminus protein for any of the donors (data not shown). Experiments were repeated 3 times for each donor with consistent results. These results reflect immunologic memory of exposure to influenza by HLA A2-positive individuals. This is because primary in vitro antigen stimulation of naïve cells does not lead to $\gamma$-IFN release. The lack of response to E2 protein may indicate a low frequency of E2-specific CTL in the peripheral blood of normal volunteers or poor processing and presentation of the whole protein to CTL by nonprofessional APC.

This phenomenon was studied further using functional monocyte-derived DC pulsed with E2 C-terminus protein, HLA A2 influenza peptide or no antigen, to stimulate autologous CD8+enriched T cells. After 7 days, the T cells were restimulated with fresh E2 C-terminus-pulsed DC or DC alone, or with E2 Cterminus-pulsed PBMC or PBMC alone. $\gamma$-IFN ELISPOT was performed at 4 days after the first or second stimulation (Fig. 1). Experiments were repeated 3 times for each donor with consistent results.
HLA-A2 -ve Donor A

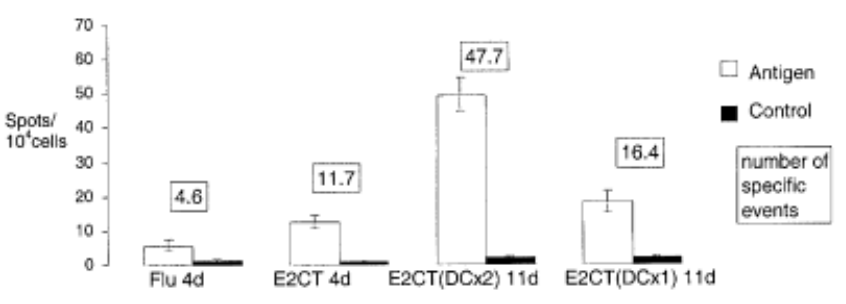

HLA-A2 +ve Donor B

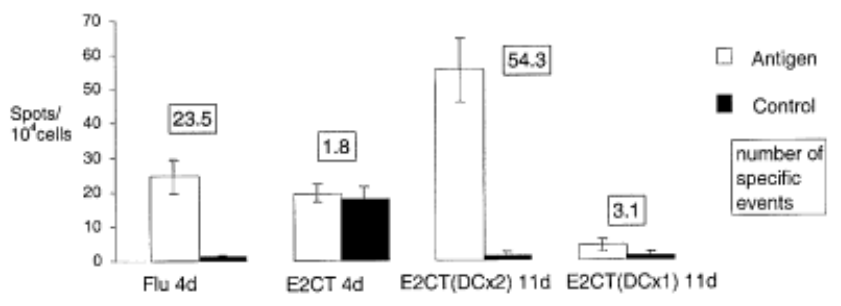

HLA-A2 +ve Donor C

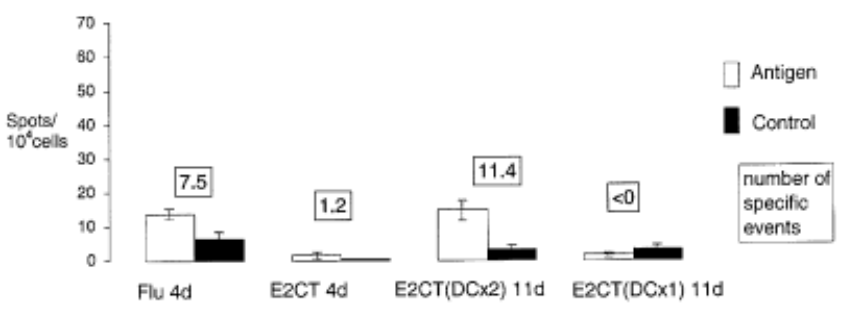

Figure 1 - ELISPOT data for 3 normal donors showing the mean number of spots and standard errors per $10^{4}$ cells after 4 days stimulation with dendritic cells (DC) pulsed with flu peptide (Flu 4d) or E2 C-terminus protein (E2CT 4d) and after 11 days stimulation with DC pulsed with E2 C-terminus protein [E2CT(DCx2) 11d] or 11 days stimulation with DC pulsed with E2 C-terminus (first 7 days) followed by stimulation with PBMC pulsed with E2 C-terminus (second 4 days) [E2CT(DCx1) 11d]. The number of specific events = number of spots in control wells-number of spots in antigen-stimulated wells.

For the HLA A2-negative donor A, 11.7 specific events $/ 10^{4}$ cells were seen after the first stimulation with DC pulsed with E2 C-terminus protein compared with 4.6 specific events $/ 10^{4}$ cells with HLA A2-restricted flu peptide. For HLA A2-positive donors $\mathrm{B}$ and $\mathrm{C}, 1.8$ and 1.2 specific events $/ 10^{4}$ cells, respectively, were seen with DC pulsed with E2 C-terminus protein compared with 23.5 and 7.5 specific events $/ 10^{4}$ cells after 4 days' stimulation with DC pulsed with flu peptide. These results show evidence of a higher frequency of memory $\mathrm{T}$ cells to the flu peptide in HLA A2-matched individuals than that detected after PBMC stimulation.

Four days after a second stimulation with DC + E2 C-terminus protein, the number of specific events for donors $\mathrm{B}$ and $\mathrm{C}$ was 54.3 and 11.4 per $10^{4}$ cells, respectively, compared with 1.8 and 1.2 per $10^{4}$ cells after the first stimulation. The same increase in specific events was not seen when the restimulation at 7 days was with PBMC + E2 C-terminus (3.1 and $<0$ specific events $/ 10^{4}$ cells for donors $\mathrm{B}$ and $\mathrm{C}$, respectively). For donor $\mathrm{A}$, the 2 stimulations with DC loaded with HPV 16 E2 C-terminus caused the number of specific events to increase 4 -fold from 11.7 per $10^{4}$ cells to 47.7 per $10^{4}$ cells. Unlike the other donors, donor A also showed an increase in the number of specific events after DC + E2 C- 


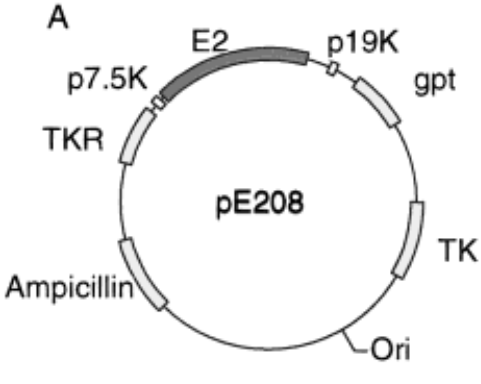

B

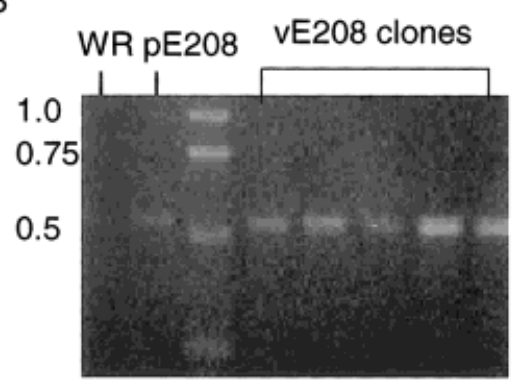

C

(i)

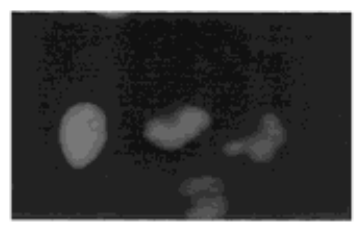

(ii)

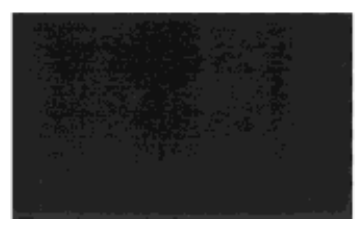

D

\section{CV-1 cells}
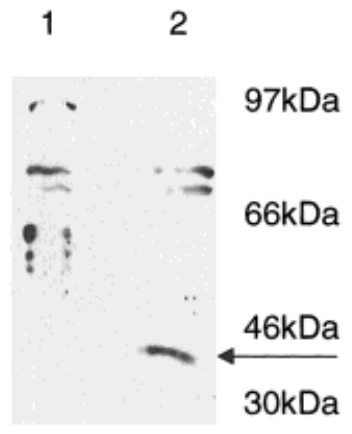

\section{E2} $\left(M_{\mathrm{r}}=42 \mathrm{kDa}\right)$
Figure 2 - Characterization of vE208, a recombinant vaccinia virus encoding human papillomavirus (HPV) type 16 E2 protein (HPV 16 E2). (a) Plasmid map of the vaccinia insertion vector encoding HPV 16 E2. The expression cassette of HPV $16 \mathrm{E} 2$ driven by the $\mathrm{p} 7.5 \mathrm{~K}$ promoter and gpt (guanine phophoribosyltransferase) driven by the $\mathrm{p} 19 \mathrm{~K}$ promoter is flanked by vaccinia $t k$ sequences to allow homologous recombination. (b) Clones with the correct size of insert by PCR. WR, wild-type vaccinia; pE208, E2 vaccinia transfection plasmid (1 ng); vE208, vaccinia-E2. MBI $1 \mathrm{~Kb}$ DNA ladder. 25 cycles PCR, annealing temperature $40^{\circ} \mathrm{C}$ for 1 min. (c) Immunofluorescent-staining of HeLa cells infected at $10 \mathrm{pfu} / \mathrm{cell}$ with (i) vE208 and (ii) WR, stained with polyclonal rabbit anti-E2 C-terminus antisera at dilutions of 1:100. (d) Western blot of E2 protein expression by CV-1 cells. Reduced $10 \%$ SDS-PAGE of cells infected with WR (lane 1) and cells infected with vE208 (lane 2), detected with 1:50 dilution of polyclonal rabbit anti-E2 C-terminus antibody. terminus for 7 days followed by PBMC + E2 C-terminus for 4 days ( 16.4 per $10^{4}$ cells).

\section{Characterization of vaccinia-E2}

To generate E2-expressing target cells for cytotoxicity assays, we constructed a recombinant vaccinia virus encoding HPV 16 E2, which was used to infect autologous Epstein-Barr virus-transformed LCL (Fig. 2). Five clones of vaccinia-E2 were isolated after 3 rounds of plaque purification and tested for the successful insertion of the E2 gene by PCR (Fig. $2 b$ ). Recombinant virus was used to infect HeLa cells at $10 \mathrm{pfu} / \mathrm{cell}$ and expression of the E2 protein was confirmed by immunofluorescence microscopy, using a rabbit anti-E2 C-terminus polyclonal antibody. All 5 clones proved positive for E2 protein expression (Fig. 2c). A single clone was selected and designated vE208. vE208-infected CV-1 cells were also analyzed by Western blot for E2 protein expression. The Western blot (Fig. 2d) shows a band near the predicted molecular weight of the full-length E2 protein of $42 \mathrm{kDa}$ with the rabbit anti C-terminus antibody in the CV-1 cells infected with vE208, but not in the CV-1 cells infected with WR.

\section{E2-specific CD8+ T-cell responses: cytotoxicity assays}

$\mathrm{T}$-cell responses were tested by ${ }^{51} \mathrm{Cr}$ release assays after 2, 3, 4 and 5 stimulations with autologous monocyte-derived DC pulsed with E2 C-terminus protein or with DC alone. Target cells were autologous LCL alone, autologous LCL infected with WR, autologous LCL infected with vE208 and K562 cells. Target cell lysis by $\mathrm{T}$ cells stimulated with DC pulsed with $\mathrm{E} 2 \mathrm{C}$-terminus protein was compared with $\mathrm{T}$ cells stimulated with $\mathrm{DC}$ in the absence of E2. Assays were repeated 4 times for each donor with comparable results. Donors $\mathrm{B}$ and $\mathrm{C}$ consistently showed evidence of E2specific lysis of vE208-infected autologous LCL (Fig. 3). E2specific CTL did not lyse untreated autologous LCL or LCL infected with WR and showed low levels of cytotoxicity against natural killer cell-sensitive K562 cells (less than 6\% lysis). Furthermore, $\mathrm{T}$ cells stimulated with DC in the absence of E2 failed to demonstrate lysis of vE208-labeled targets. Phenotypically,
CTL populations were $\mathrm{CD} 3+/ \mathrm{CD} 8+$ and $\mathrm{CD} 4-$ as assessed by flow cytometry. E2-specific lysis first became apparent after 3 or 4 stimulations of T-cell cultures, depending on the donor. Donor A did not demonstrate E2-specific lysis of vE208-infected autologous LCL.

\section{DISCUSSION}

In this study, we have investigated T-cell responses to the HPV 16 E2 C-terminus in normal volunteers. Populations of functional monocyte-derived DC were generated with surface markers as previously described. ${ }^{33-36}$ They were pulsed with E2 C-terminus protein and used to stimulate autologous $\mathrm{T}$ cells over several rounds of stimulation and these were tested for specific activity by ELISPOT and ${ }^{51} \mathrm{Cr}$-release assay. ELISPOT is a rapid and sensitive assay that detects $\gamma$-IFN secretion by antigen-specific memory $\mathrm{T}$ cells in response to antigen exposure. ${ }^{32,37,38}$ Usually, the ELISPOT assay uses HLA-restricted peptides as a source of antigen, but the assay was adapted in the present study to allow the potential detection of memory and primary T-cell responses to an HPV protein antigen after it has been processed and presented by autologous APC. This approach has the obvious advantage that it more closely resembles antigen presentation in vivo and allows CTL responses to be studied regardless of an individual's tissue type.

Primary in vitro stimulation of naïve T cells can lead to IL-2 production and proliferation but not $\gamma$-IFN secretion; this occurs following re-encounter with antigen. ${ }^{39}$ Unstimulated PBMC pulsed with E2 C-terminus protein did not induce specific $\gamma$-IFN secretion by $\mathrm{T}$ cells in any of the donors. This finding is consistent with a frequency of memory CTL in the peripheral blood of normal volunteers below the threshold of detection. However, T-cell responses to HPV 16 E2 were demonstrated by ELISPOT after a single stimulation of T-cell cultures with protein-loaded DC for donor A, and after 2 stimulations for donors B and C. Thus in individual A there may be a memory response that is detectable after appropriate antigen presentation or a small expansion in vitro. This finding was in contrast to the ${ }^{51} \mathrm{Cr}$-release assays in which a 
(a)

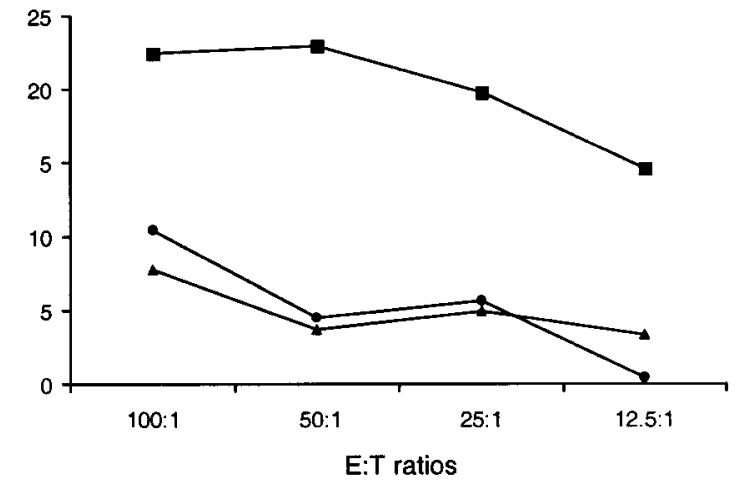

$\%$ lysis

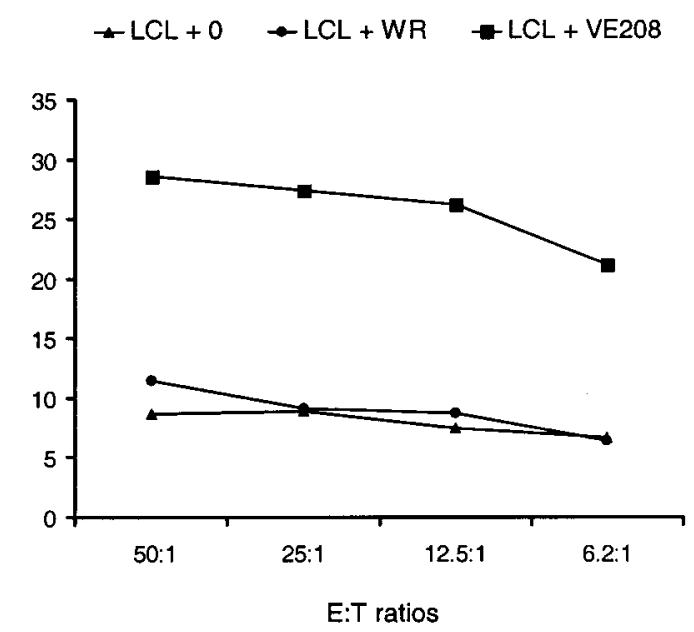

(b)

Figure 3 - Cytotoxicity assays for donors B and C after stimulation of T-cell cultures with autologous dendritic cells (DC) pulsed with E2 C-terminus protein. (a) Donor B anti E2 T cells after 3 stimulations and $(b)$ donor $\mathrm{C}$ anti $\mathrm{E} 2 \mathrm{~T}$ cells after 4 stimulations in vitro. E2-specific lysis is measured by comparing lysis of ${ }^{51} \mathrm{Cr}$-labeled autologous lymphoblastoid cell lines (LCL) infected with vaccinia-E2 (LCL + vE208) with ${ }^{51} \mathrm{Cr}$-labeled LCL infected with wild-type vaccinia $(\mathrm{LCL}+\mathrm{WR})$ or unlabeled LCL $(\mathrm{LCL}+0)$ at a number of different effector:target (E:T) ratios.

minimum of 3 in vitro stimulations were required before E2specific lysis became apparent. Donor A was female, HLA A2 negative with no history of influenza; donor B was male, HLA A2 positive with a history of 2 recent episodes of influenza; and donor $\mathrm{C}$ was male, HLA A2 positive with a questionable history of influenza. After a single stimulation with either PBMC or DC pulsed with flu peptide, $\mathrm{T}$ cells from donors $\mathrm{B}$ and $\mathrm{C}$ showed evidence of a memory response to influenza. However, the frequency detected was 5.3- and 11.3-fold more with DC stimulation than with PBMC stimulation for donors B and C, respectively. By contrast, no significant E2 responses were seen in these donors. Donor A showed some evidence of a "memory" response to E2 compared with the irrelevant test for an HLA A2 flu peptide response after the same 4-day stimulation procedure. This E2 memory response could be enhanced or boosted by a second stimulation with protein-loaded DC $\left(47.7 / 10^{4}\right.$ cells $)$ or PBMC $\left(16.4 / 10^{4}\right.$ cells). This result might reflect priming of naïve T cells or an expansion of the existing memory response with antigen effectively presented by the DC. A memory response to HPV 16 E2 in a healthy volunteer may be explained by previous subclinical exposure to the virus. Genital HPV infection rates in women with normal cervical cytology varies with age and the number of lifetime sexual partners, but may be as high as $25 \%$ in women in their early $20 \mathrm{~s} .{ }^{40}$ Many of these infections are transient and disappear without ever causing dysplasia. ${ }^{41-43}$

Donors $\mathrm{B}$ and $\mathrm{C}$ did not have evidence of memory T-cell responses to HPV $16 \mathrm{E} 2$, but putative primary T-cell responses could be generated in vitro after 2 stimulations with E2 C-terminus protein-loaded DC and quantified by ELISPOT assays. These apparent primary $\mathrm{T}$-cell responses required antigen processing and presentation by DC as PBMC appeared to be ineffective and insufficient for eliciting the response. This finding is in contrast to donor $\mathrm{A}$ in whom expansion of the existing memory response to E2 could be supported by DC or PBMC, although the magnitude of response was 3-fold lower in the latter case. This finding is consistent with the theory that PBMC are able to restimulate previously activated $\mathrm{T}$ cells but are unable to prime naïve $\mathrm{T}$ cells. Studies by van der Burg et al. ${ }^{44}$ have shown that after primary activation of T cells, $\gamma$-IFN release only begins after stimulation with antigen for a second time. Using overlapping peptides to HPV 16 E7 they have mapped the E7 peptide epitope responses in normal individuals and patients with CIN or cervical cancer. The exposure to the pathogen is correlated with positive short-term ELISPOT assays in about $30 \%$ of cases. ${ }^{44}$

In the present study, all 3 donors demonstrated T-cell responses to E2 by $\gamma$-IFN ELISPOT, and only 2 of the 3 showed E2-specific cytotoxicity by ${ }^{51} \mathrm{Cr}$-release assays. This result required a minimum of 3 stimulations so it is not possible to know whether these are primary or memory-derived effectors. It is possible that the anti-E2 T cells generated for donor A were $\gamma$-IFN-releasing but not active in CTL assays. In any case, the specific release of $\gamma$-IFN by CTL may be sufficient to promote the eradication of HPV infection even in the absence of cytotoxicity. Although little is known about natural anti-HPV immunity, cytotoxicity and the release of type 1 cytokines such as $\gamma$-IFN and IL-2 are thought to be essential for effecting viral clearance. ${ }^{45}$ Whether antigen-specific cytotoxicity or antigen-specific cytokine release plays the dominant role in viral clearance has yet to be established, but efficient anti-HPV immunity probably depends on a complex interaction of both these and other immune mechanisms.

In this report we have demonstrated that HPV 16 E2-specific CTL can be elicited in normal volunteers using E2 C-terminus protein-pulsed autologous DC. The resulting T-cell populations are active in the $\gamma$-IFN ELISPOT system after 1 or 2 stimulations in vitro, and by ${ }^{51} \mathrm{Cr}$-release assays after 3 or 4 stimulations for 2 of the 3 donors. The utility of this type of methodology in the study of natural immune responses to E2 in cervical neoplasia patients now needs to be investigated and compared with the overlapping peptide approaches that have been used for HPV oncogenes. ${ }^{44}$

\section{ACKNOWLEDGEMENTS}

The research of P.L.S., M.D.B., D.J.B. and S.N.S. was supported by the Cancer Research Campaign. J.L.P. was supported by a PhD studentship from the BBSRC and Enact Pharma PLC. K.G. was supported by a research grant from the Royal Society. The Joseph Starkey Fellowship from Wigan Cancer Research Fund and The Cancer Research Campaign supported E.J.D.

We thank Ms. Y. Connolly for the immunofluorescence studies and Dr. S. Dermime for expert advice.

\section{REFERENCES}

1. Bosch FX, Manos MM, Munoz N, et al. Prevalence of human papillomavirus in cervical cancer: a worldwide perspective. International biological study on cervical cancer (IBSCC) study group. J Natl Cancer Inst 1995;87:796-802.
2. Walboomers JM, Jacobs MV, Manos MM, et al. Human papillomavirus is a necessary cause of invasive cervical cancer worldwide. J Pathol 1999;189:12-9.

3. Ho GY, Buck RD, Klein S, et al. Persistent genital human papillo- 
mavirus infection as a risk factor for persistent cervical dysplasia. J Natl Cancer Inst 1995;87:1365-71.

4. Rozendaal L, Walboomers JMM, Van der Linden JC. High risk human papillomavirus in cytomorphological normal smears has a high predictive value for development of severe dysplasia. Int J Cancer 1996;68:766-9.

5. Spitzer M. Lower genital tract intraepithelial neoplasia in HIV-infected women: guidelines for evaluation and management. Obstet Gynecol Surv 1999;54:131-7.

6. Ho GY, Burk RD, Fleming I, et al. Risk of genital human papillomavirus infection in women with human immunodeficiency virusinduced immunosuppression. Int J Cancer 1994;56:788-92.

7. Petry KW, Scheffel D, Bode U, et al. Cellular immunodeficiency enhances the progression of human papillomavirus-associated cervical lesions. Int J Cancer 1994;57:836-40.

8. Muller M, Viscidi RP, Sun Y, et al. Antibodies to HPV 16 E6 and E7 proteins as markers for HPV 16 associated invasive cancer. Virology 1992;187:508-14.

9. de Gruijl TD, Bontkes HJ, Stukart MJ, et al. Immunoglobulin G responses against human papillomavirus type 16 virus-like particles in a prospective nonintervention cohort study of women with cervical intraepithelial neoplasia. J Natl Cancer Inst 1997;89:630-8.

10. Rocha-Zavaleta L, Jordan D, Pepper S, et al. Differences in serological IgA responses to recombinant baculovirus-derived human papillomavirus E2 protein in the natural history of cervical neoplasia. Br J Cancer 1997:75:1144-50.

11. Man S. Human cellular immune responses against human papillomaviruses in cervical neoplasia. In: Expert reviews in molecular medicine; 1998. Accession number txt001smc. ISSN1462-3974.

12. Halbert CL, Demers GW, Galloway DA. The E7 gene of human papillomavirus type 16 is sufficient for immortalization of human epithelial cells. J Virol 1991;65:473-8.

13. von Knebel Doeberitz M, Rittmuller C, zur Hausen $\mathrm{H}$, et al. Inhibition of tumorigenicity of cervical cancer cells in nude mice by HPV E6-E7 anti-sense RNA. Int J Cancer 1992;51:831-4.

14. Benson JD, Howley PM. Amino-terminal domains of the bovine papillomavirus type $1 \mathrm{E} 1$ and E2 proteins participate in complex formation. J Virol 1995;69:4364-72

15. Androphy EJ, Lowy DR, Schiller JT. Bovine papillomavirus E2 trans-activating gene product binds to specific sites in papillomavirus DNA. Nature 1987;325(6099):70-3.

16. Giri I, Yaniv M. Structural and mutational analysis of E2 transactivating proteins of papillomaviruses reveals three distinct functional domains. EMBO J 1988;7:2823-9.

17. Stubenrauch F, Colbert AM, Laimins LA. Transactivation by the E2 protein of oncogenic human papillomavirus type 31 is not essential for early and late viral functions. J Virol 1998;72:8115-23.

18. Sedman J, Stenlund A. Co-operative interaction between the initiator E1 and the transcriptional activator E2 is required for replicator specific DNA replication of bovine papillomavirus in vivo and in vitro. EMBO J 1995;14:6218-28.

19. McBride AA, Romanczuk H, Howley PM. The papillomavirus E2 regulatory proteins. J Biol Chem 1991;266:18411-4.

20. Stevenson M, Hudson LC, Burns JE, et al. Inverse relationship between the expression of the human papillomavirus type 16 transcription factor E2 and virus DNA copy number during the progression of cervical intraepithelial neoplasia. J Gen Virol 2000;81(Pt 7):1825-32.

21. Han R, Cladel NM, Reed CA, et al. DNA vaccination prevents and/or delays carcinoma development of papillomavirus-induced skin papillomas on rabbits. J Virol 2000;74:9712-6.

22. Han R, Reed CA, Cladel NM, et al. Immunization of rabbits with cottontail rabbit papillomavirus E1 and E2 genes: protective immunity induced by gene gun-mediated intracutaneous delivery but not by intramuscular injection. Vaccine 2000;18:2937-44.

23. Schiller JT, Hidesheim A. Developing HPV virus-like particle vaccines to prevent cervical cancer: a progress report. J Clin Virol 2000;19:67-74.

24. Graham DA, Herrington CS. HPV-16 E2 gene disruption and sequence variation in CIN 3 lesions and invasive squamous cell carci- nomas of the cervix: relation to numerical chromosome abnormalities. Mol Pathol 2000;53:201-6.

25. Lehtinen M, Hibma MH, Stellato G, et al. Human T cell epitopes overlap B cell and putative cytotoxic T cell epitopes in the E2 protein of human papillomavirus type 16. Biochem Biophys Res Commun 1995;209:541-546

26. Bontkes HJ, de Gruijl TD, Bijl A, Verheijen RH, Meijer CJ, Scheper $\mathrm{RJ}$, et al. Human papillomavirus type 16 E2-specific T-helper lymphocyte responses in patients with cervical intraepithelial neoplasia. J Gen Virol 1999:80(Pt 9):2453-9.

27. Konya J, Eklund C, AfGeijersstam V, et al. Identification of a cytotoxic T-lymphocyte epitope in the human papillomavirus type $16 \mathrm{E} 2$ protein. J Gen Virol 1997;78:2615-20.

28. Shimonkevitz R, Kappler J, Marrack P, et al. Antigen recognition by $\mathrm{H}-2$-restricted T cells. I. Cell-free antigen processing. J Exp Med 1983;158:303-16.

29. McDevitt HO, Tyan ML. Genetic control of the antibody response in inbred mice. Transfer of response by spleen cells and linkage to the major histocompatibility (H-2) locus. J Exp Med 1968;128:1-11.

30. Austyn J. Dendritic cells. Curr Opin Hematol 1998;5:3-15.

31. Webster K, Parish J, Pandya M, et al. The human papillomavirus (HPV) 16 E2 protein induces apoptosis in the absence of other HPV proteins and via a p53-dependent pathway. J Biol Chem 2000;275: 87-94.

32. Schmittel A, Keilholz U, Scheibenbogen C. Evaluation of the interferon-gamma ELISPOT-assay for quantification of peptide specific $\mathrm{T}$ lymphocytes from peripheral blood. J Immunol Methods 1997;210: $167-74$

33. Agger R, Crowley MT, Witmer Pack MD. The surface of dendritic cells in the mouse as studied with monoclonal antibodies. Int Rev Immunol 1990;6:89-101.

34. Mayordomo JL, Zorina T, Storkus WJ, et al. Bone marrow-derived dendritic cells serve as potent adjuvants for peptide-based antitumour vaccines. Stem Cells 1997;15:94-103.

35. Steinman RM. The dendritic cell system and its role in immunogenicity. Annu Rev Immunol 1991;9:271-96.

36. de Wynter EA, Buck D, Hart C, et al. CD34+AC133+ cells isolated from cord blood are highly enriched in long-term culture-initiating cells, NOD/SCID-repopulating cells and dendritic cell progenitors. Stem Cells 1998;16:387-96.

37. Lalvani A, Brookes R, Hambleton S, et al. Rapid effector function in CD8 + memory T cells. J Exp Med 1997;186:859-65.

38. McCutcheon M, Wehner N, Wensky A, et al. A sensitive ELISPOT assay to detect low-frequency human $\mathrm{T}$ lymphocytes. J Immunol Methods 1997;210:149-66.

39. Sallusto F, Lenig D, Forster R, et al. Two subsets of memory $T$ lymphocytes with distinct homing potentials and effector functions. Nature 1999;401(6754):708-12.

40. Melkert PJW, Hopman E, van den Brule AJC, et al. Prevalence of HPV in cytomorphologically normal smears as determined by the polymerase chain reaction is age-dependent. Int J Cancer 1993;53: 919-23.

41. Walboomers JMM, Jacobs MV, van Oostveen JW, et al. Detection of human papillomavirus infections and possible clinical implications. In: Gross G, von Krogh G, eds. Human papillomavirus infections in dermatovenereology. New York: CRC Press, 1997. 341-64.

42. Schiffman MH. Epidemiology of cervical human papillomavirus infections. In: Zur Hausen H, ed. Human pathogenic papillomaviruses. Current topics in microbiology and immunology. Berlin: Springer Verlag, 1994. 55-81.

43. Ho GY, Bierman R, Beardsley L, et al. Natural history of cervicovaginal papillomavirus infection in young women. N Engl J Med 1998;338:423-8

44. van der Burg SH, Ressing ME, Kwappenberg KMC, et al. Natural T-helper immunity against human papillomavirus type 16 (HPV 16) E7-derived peptide epitopes in patients with HPV 16 positive cervical lesions: identification of three human leukocyte antigen class II restricted epitopes. Int J Cancer 2001;91:612-8.

45. Zinkernagel RM. Immunology taught by viruses. Science 1996; 271:173-8 